\title{
Intuitive Evidence and Experimental Philosophy
}

\author{
Jonathan Jenkins Ichikawa
}

April 20, 2015

\section{Introduction}

No discipline that affords a central evidential role to an unreliable source is in good standing. So if analytic philosophy affords a central evidential role to intuitions, then if intuitions are unreliable, then analytic philosophy is not in good standing. ${ }^{1}$ So much, I think, is uncontroversial. Some of the early critiques of traditional analytic methods by experimental philosophers assumed that analytic philosophy gives intuitions central roles, and, citing data that suggested that intuitions may be unreliable, argued on these grounds that analytic philosophy might not be in good standing. For example, in their famous paper alleging cross-cultural diversity with respect to epistemic intuitions, Weinberg et. al describe their target thus:

The family of strategies that we want to focus on all accord a central role to what we call epistemic intuitions. Thus we will call this family of strategies Intuition Driven Romanticism (or IDR). As we use the notion, an epistemic intuition is simply a spontaneous judgment about the epistemic properties of some specific case - a judgment for which the person making the judgment may be able to offer no plausible justification. To count as an Intuition Driven Romantic strategy for discovering or testing epistemic norms, the following three conditions must be satisfied: (i) The strategy must take epistemic intuitions as data or input. (It can also exploit other sorts of data.)... Weinberg et al. (2001, p. 432)

In recent years, some defenders of traditional philosophical methodology have argued that critiques like this one are mistaken in assuming that intuitions play central evidential roles in traditional philosophical methods. According to this kind of response, experimental philosophers attack a straw man; it doesn't matter whether intuitions are reliable, because philosophers don't use intuitions in the way assumed. Deutsch (2010), Williamson (2007), and Cappelen (2012) all defend traditional methods in something like this way. I also endorsed something like this line in Ichikawa (2014a).

In this contribution, I will follow up on this sort of defence of traditional philosophical methods in three ways. In $\S 1$, I will rehearse and extend some of my reasons for challenging the idea that traditional methods depend on intuitions in an evidential role. (My reasons are very different from those discussed in (Cappelen, 2012).) I will also engage with some

\footnotetext{
${ }^{1}$ Some experimentalist critics of traditional philosophical methods do not charge that intuition is unreliable, but that it is epistemically deficient in some weaker way-e.g. the 'hopelessness' of Weinberg (2007).
} 
recent more sophisticated attempts to establish the idea that intuitions play evidential roles in philosophy, such as that of Chudnoff (2013). In §2, I will consider and argue against a dismissive response to such positions from experimental philosophers, who consider the question of philosophical reliance on intuitions to be irrelevant to the experimentalist critique. But in $\S 3$, I will argue that it would also be a mistake to conclude (as Herman Cappelen does) that the critique is rendered totally irrelevant by the denial of the evidential role of intuitions; I defend a more moderate view on which the bearing of experimental studies of philosophical intuitions is relevant for philosophical methodology, but only in a relatively limited way.

\section{Intuitions and Evidence}

What would it be for intuitions to play evidential roles in philosophy? According to a psychologistic model, propositions of the form I have the intuition that $p$, typically known via introspection, play fundamental evidential roles. Jessica Brown (2011) defends such a model. According to her version of the view, in paradigmatic cases one achieves philosophical knowledge by beginning with psychological evidence concerning what intuitions one has, and bases one's nonpsychological philosophical conclusions on such evidence. Since, Brown thinks, the psychological episodes that are intuitions are in fact reliable indicators of the truth of their contents, those contents can end up justified, or even known, on such grounds. ${ }^{2}$

The psychologistic model is perhaps the clearest instance of a view on which intuitions play central evidential roles, but it is not the only one. One may also hold that the mental episodes that are intuitions play important evidential roles without themselves being essential evidence - one might hold, for instance, that intuitions provide their contents as evidence. In general, the contents of intuitions are not psychological. For example, if I have the intuition that a statue would cease to exist when smashed, the content of the intuition is the nonpsychological claim about the statue.

One might hold that intuitions always provide their contents as evidence, but I do not consider this view plausible; I think there are good reasons to think that (a) some intuitions have false propositions as contents, ${ }^{3}$ and (b) false propositions are never among one's evidence. ${ }^{4}$ So a more plausible version of the nonpsychologistic view of intuitions is that in some suitable cases, one possesses a proposition as evidence by virtue of having an intuition with that proposition as its content. Even still, however, this claim must be interpreted carefully - in particular, that 'by virtue of' must be read in a suitably strong way. Assuming that evidence can be established inferentially, for example, anyone should admit that there are some possible cases where the intuition that $\mathrm{p}$ plays a role in establishing $\mathrm{p}$ as evidence. For example, if one knows antecedently that my intuition about whether $\mathrm{p}$ will

\footnotetext{
${ }^{2}$ Brown argues (pp. 512-13) that an externalist approach like the reliabilist one described here is necessary to defend the psychologistic model from skeptical worries. But other defenders of similar models, such as Chudnoff (2013), develop their views in internalist ways.

${ }^{3}$ Ludwig (2007) argues that 'intuition' is factive; nothing counts as an 'intuition' unless it is the successful exercise of a conceptual competence, which will always issue into truth. This seems to me rather clearly to be a somewhat revolutionary sense of the term. Peter Singer knows full well that many people have the intuition that one has special moral obligations to one's kin; he thinks that intuition is mistaken. Whether or not his ethical view is correct, he is not contradicting himself by thinking that these are false intuitions.

${ }^{4}$ Rizzieri (2009) gives dissent; I agree with Unger (1975), Williamson (2000), and Littlejohn (2013) that evidence cannot be false. I am particularly impressed by this argument, which is related to the discussion of Williamson (2000, ch. 9): if one could have false evidence, then one's evidence could entail a false hypothesis, which would mean that one has conclusive evidence for something false. But by definition, if I have conclusive evidence for something, it must be true.
} 
be a correct intuition, then establishing that I have the intuition that $\mathrm{p}$ will conclusively establish p. ${ }^{5}$ The interesting epistemic claim in the area is the one that there is a stronger connection between intuition and evidence - for instance, that it is in the nature of intuition that it provide, at least in central cases, its content as evidence. Or perhaps that there is a law or a general epistemic principle to the effect that intuitions' contents count as evidence. It is not enough to establish merely that, combined with some possible background knowledge, an intuition may provide its content as evidence. (Combined with some possible background knowledge, anything can be evidence for anything logically compatible with it.)

Benjamin Jarvis and I have called the view that intuitions play such evidential roles "experientialist rationalism". We argue that all such views are false. ${ }^{6}$ Since this question plays a central role in the question of the relevance of experimental data about intuitions, it is worthwhile to summarise some of the considerations in favour of this claim here.

The acquisition of evidence in favour of $p$ can play an important role in coming to a justified belief that $p$, but it isn't the only relevant factor. In addition to having the evidence, a subject must respond appropriately to it. Bruce may have figured out that the thief is after the diamonds, while Dick still has no idea what's going to happen next- this, even though they share all the same evidence. Acquiring the evidence gives one some of what one needs, but not everything; rational skill dictates how the evidence will be used. Jarvis and I use the term propositional justification for the state of having sufficient evidence to draw a particular conclusion, whether or not the person has responded to the evidence in the rational way. A belief that is properly formed on the basis of the relevant evidence is doxastically justified. The terminological decisions aren't the important part - the point to emphasise is that evidence is relevant at that first stage of inquiry. Evidence for $p$ gives one reason to believe that $p$, whether or not he or she actually believes it (or indeed, if he or she does actually believe it, whether or not he or she believes it for a good reason).

With this background in place, we are now in a position to express a central argument against the idea that intuitions provide evidence in a priori cases. Consider this case, which I introduced in Ichikawa (2014b, pp. 201-2):

Boris and Natasha ... are playing chess. Natasha is playing white; it is her move. The position of the pieces is as given [below]:

Natasha has available a move to win the game; Rh3\# (moving her rook to the far right of the board) places the black king in checkmate. Bullwinkle knows the rules of chess, but he is nevertheless unaware that Natasha has available a move to win the game. His ignorance shouldn't be too surprising, because, it turns out, he is blindfolded, and can't see the board. He has no idea where the pieces are, so of course he doesn't know that Natasha is in a position to win.

But what happens next is slightly more interesting. Bullwinkle's blindfold slips off, and for the first time, he sees the board and the position of each piece. Now he knows a lot more about the game. But, let's suppose, he still doesn't know that Natasha is in a position to win. You see, Bullwinkle isn't a very experienced chess player, and although he knows where each piece is, and knows all the rules of chess, he hasn't noticed that Rh3 would put Boris in checkmate.

The key moment to consider is the one after the blindfold slips. Now Bullwinkle has the relevant perceptual experiences - he can see the board. Although he still doesn't know that

\footnotetext{
${ }^{5}$ Whether p could thereby be evidence depends on one's theory of evidence; if Williamson (2000, ch. 9) is correct, then it certainly could.

${ }^{6}$ Ichikawa and Jarvis (2013, ch. 11)
} 


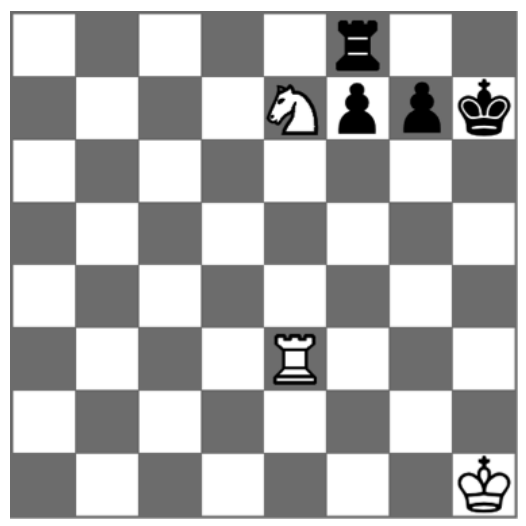

Figure 1: Boris and Natasha's Game

Natasha can win on this turn, he has conclusive evidence that she can. In the terminology above, he now has propositional justification for the proposition that Natasha will win, even though he doesn't know it, or even believe it, even if he is contemplating the question. This constitutes a rational shortcoming; by remaining agnostic about that for which he has conclusive reason to believe, Bullwinkle demonstrates that he is a less than ideally rational agent. Importantly, Bullwinkle's position manifests rational failure only after his blindfold slipped; even an ideal rational agent will be agnostic about whether Natasha can win this turn, if he can't see the board. But once the perceptual experiences obtain, Bullwinkle faces rational pressure towards accepting this conclusion.

It is sufficient for this kind of rational pressure that Bullwinkle has the experiences that justify true beliefs about the state of the game - the rules of chess, the position of the pieces, that it is Natasha's turn, and that she is playing white. We do not need to stipulate that Bullwinkle has an intuition with the content that Natasha can win this turn. One could consider such a version of the case - perhaps Bullwinkle has enough chess experience to have developed subpersonal intuitions of this sort, and he's failing to take advantage of them in this instance - but it is not necessary to suppose that he has this kind of chess ability to establish the verdict that he is manifesting rational limitations. This means that there is rational pressure in this case that does not depend on the presence of intuition. ${ }^{7}$ And this seems to apply to all rational necessities - the truths of logic and arithmetic, socalled 'conceptual truths', the parts of philosophy people have called 'analytic', etc. This is the my first argument against intuitions in evidential roles - the argument from 'opaque

\footnotetext{
${ }^{7}$ One might wonder, as Jennifer Nado did in personal correspondence, whether it's necessary for the kind of rational pressure I'm describing that Bullwinkle could form the intuition under the circumstances. I make three observations in response. First, even if it were true that Bullwinkle only has propositional justification if he is capable of forming the relevant intuition, this would not suffice to defend experimentalist rationalism from the critique; according to experimentalist rationalism, it is something about the experience of an intuition itself that does justificatory work. (For example, on the view of Chudnoff (2013), the phenomenology of intuitions plays the relevant role.) Positing a kind of counterfactual intuition as a necessary condition for propositional justification does not support any central epistemic role for actual intuitions. Second, in the plausible ways of spelling out this case, there is a straightforward sense in which Bullwinkle could have the relevant intuition - this is what would happen if he thought a little harder and more carefully. Third, Jarvis and I argue that the counterfactual necessary condition is false. See Ichikawa and Jarvis (2013, pp. 282-83). So even if Bullwinkle couldn't have the intuition, that doesn't prevent his situation from constituting a rational failure. Indeed, it is reasonably natural to think that his inability to have such intuitions contributes, causally or constitutively, to his rational failure.
} 
irrationality'. ${ }^{8}$ There is rational pressure in favour of accepting these truths, even if subjects are unaware of such pressure, and don't even feel an inclination to adopt it. ${ }^{9}$

But once we think that in cases like Bullwinkle's there is rational pressure that does not depend on intuitions, there seems to be little motivation to suppose that intuitions are playing central roles in those cases in which they are present. ${ }^{10}$ I suppose there's no contradiction in the idea that, in a counterfactual version of the case where Bullwinkle does have the intuition, that intuition is playing justificatory roles, but in the version where it is lacking, something else plays those roles instead. But such a view seems more than a little ad hoc; I see nothing to recommend it. If the rational pressure is present regardless of the presence of the intuition, that's excellent reason to suppose that the intuition doesn't explain the rational pressure. Any role intuitions have in cognition, therefore, is quite unlike the role of perceptual experience. (The counterfactual version of the Bullwinkle story in which Bullwinkle undergoes no visual experiences of the chessboard is one in which he has no propositional justification for any particular claims about the state of the game.)

Here is a second, closely related, argument for the same conclusion. Take a subject like the ones just discussed - someone who fails to believe something for which he has conclusive reason to believe, and thereby manifests a rational deficiency, even though he has no intuition that clues him into this fact. Now suppose that over time, his cognitive capacities change. For example, suppose that Bullwinkle gets better at imagining various possible chess moves, and recognising important patterns of pieces. Now, if confronted like a board like that above, Bullwinkle will have the strong intuition, which he'd go on to accept, that white can win on this move. Such a change constitutes a rational improvement; if so, the standards of rationality are not relative to these kinds of intuitions and cognitive abilities, the way they are relative to perceptual experience.

Elijah Chudnoff (2013) has given the most thorough recent defence of a strong analogy between intuition and perceptual experience of which I am aware; it is useful to consider the argument above in the context of his defence of an evidential role for intuitions. Chudnoff argues for this principle:

$\left(\mathrm{DIJ}^{R}\right)$ If it basically intuitively seems to you that $p$, then you thereby have some prima facie justification for believing that $p$. (94)

Chudnoff writes that $\left(\mathrm{DIJ}^{R}\right)$ is motivated primarily by reflection on examples:

Take the proposition that every concave figure can be rounded out to a convex figure that bounds a greater area in a smaller perimeter. This is a good example because it is likely not something you have thought about before. Initially it neither seems true nor seems false to you, and you neither have justification for believing it nor have justification for doubting it. After thinking about it a bit, however, it should seem true to you. (94)

This 'seeming true', Chudnoff thinks, is an intuition experience, and it is what provides the justification for accepting that conclusion. I recognize something like the phenomenology Chudnoff is describing here -initially, at $t_{1}$, one might have no idea whether a claim

\footnotetext{
${ }^{8}$ In previous work, Jarvis and I have called these cases of 'blind irrationality'.

${ }^{9}$ Note that to say there is rational pressure here leaves open many normative questions. In particular, it does not imply that one is criticizable for failing to believe what one has conclusive reason to believe. It also does not imply that if one does believe what one has such reason to believe, one has formed a doxastically justified belief. One can believe what one has reason to believe, but do so for the wrong reasons. Thanks to Michael Johnson for discussion here.

${ }^{10}$ Thanks to Jennifer Nado for reminding me of the need for this discussion.
} 
is true, and then at $t_{2}$, in a flash of insight, one realizes that it must be true. And I also agree with Chudnoff that at $t_{3}$, after this experience, one has justification to think that every concave figure can be rounded out to a convex figure that bounds a greater area in a smaller perimeter. But I do not agree with Chudnoff that the intuitive experience is the explanation for this justification. I think that considerations arising from opaque irrationality and rational improvement give us good reason to reject Chudnoff's claim that one has no justification at $t_{1}$. Recall that the relevant notion of justification here is propositional justification, not doxastic justification. ${ }^{11}$ It is obvious that I had no doxastic justification at $t_{1}$, since doxastic justification is a property of beliefs, and I didn't have the belief at $t_{1}$. The question is whether I had sufficient reason at $\mathrm{t}_{1}$ to believe that every concave figure can be rounded out to a convex figure. In other words, was my ignorance more like Bullwinkle's ignorance before his blindfold slipped, or afterwards?

Once the question is thus clarified, it seems to me clear that my failure at $t_{1}$ is much more like Bullwinkle's failure after he gains the relevant sensory experiences. My problem at $t_{1}$ isn't that I am lacking evidence - it's that I am engaging with the question with less than fully ideal rationality. I need better reasoning, not better evidence. If so, the intuitive experience is playing a role very unlike that of perceptual experience in perceptual belief. It is not providing propositional justification. ${ }^{12}$

I consider it an open question as to which domains of philosophy have this status. I am open to the idea that there are some subfields in which psychological elements do occupy central evidential roles. For example, Regina Rini (2013) argues that moral psychology proceeds via an abstraction from one's own moral commitments - the idea is that one engages in a theoretical process of reflection to determine which of one's moral commitments are idiosyncratic, and which more plausibly represent fundamental norms. Rini very sensibly observes that, given this conception, empirical evidence about the sources of one's intuitions might be very relevant. What I want to insist is that many cases of a priori reasoning do not rely on such psychological inputs. (I will return in $\S 3$ to the question of whether psychological evidence can be relevant for the evaluation of arguments in these areas.)

So I do agree with the conclusion of Cappelen (2012): it is a mischaracterization of how philosophical and other a priori reasoning works to suppose that it generally relies in a central evidential way on intuitions. (I defend this claim further in Ichikawa (2014a).) In the remainder of this paper, I will treat this as established, and turn to the question of its implications for the experimentalist critiques of philosophical methods that are often expressed in terms of intuitions. My view is intermediate between that defended by Jonathan Weinberg and Joshua Alexander - that it's completely irrelevant for this experimentalist project - and that defended by Herman Cappelen - that it justifies totally ignoring this experimentalist

\footnotetext{
${ }^{11}$ I do not think that this is a point of contention between Chudnoff and myself; see e.g. Chudnoff (2013, p. 85), where he clarifies that the notion of justification at issue in the corresponding claim about perceptual justification concerns propositional, rather than doxastic, justification. Since his broad project is to argue that intuitive experience and perceptual experience play similar roles, and since he doesn't say otherwise, I assume that Chudnoff's view is that intuitions establish propositional justification. ( Ichikawa and Jarvis (2013, p. 298) gives arguments against intuitions' playing a special role in establishing doxastic justification.)

${ }^{12}$ The very natural question of what does provide propositional justification is beyond my present scope. Ichikawa and Jarvis (2013) argues at length that in cases like this, it is a brute fact that all subjects (or at least those with the relevant concepts who are considering the question) always have such justification, regardless of experiences.
} 
project. I discuss these two extreme views in the next two sections, respectively.

\section{Relevance to Experimental Philosophy}

Timothy Williamson has also argued, in a series of influential papers, against the assumption that intuitions play important evidential roles in philosophy. ${ }^{13}$ He suggests that the reason some philosophers tend to think that philosophical conclusions are based on intuition derives from an erroneous principle of 'evidence neutrality' - the idea that for anything to be evidence for someone, it has to be the sort of thing that all parties to the debate must recognise as evidence. He argues forcefully against this principle, and suggests on this basis that, in the kinds of philosophical cases in which one might be tempted to say that an intuition is the ultimate evidence, it is actually the philosophical fact itself that is playing the evidential role, even though it is a controversial philosophical fact. Williamson's argument against intuitions as evidence differs from mine in several important ways; examining some of the responses to Williamson, and how they bear with respect to my approach, is one way to bring out these important differences.

Alexander and Weinberg (2007) give the most direct and explicit response I have seen to the Williamsonian approach. They write:

Timothy Williamson has also developed a more radical response to the restrictionist threat: rejecting the picture of philosophical practice as depending on intuitions at all! He argues that our evidence [in the relevant cases] is not any sort of mental seeming, but the facts in the world. He compares philosophical practice to scientific practice, where we do not take the perceptual seemings of the scientists as our evidence, but the facts about what they observed. Similarly, then, we should construe Gettier's evidence to be not his intellectual seeming that his case is not an instance of knowledge, but rather the modal fact itself that such a case is not an instance of knowledge. We retreat from talk of the world to talk of percepts when we (mistakenly) attempt to accommodate the skeptic; so, too, do we retreat to talk of intuitions only under the pressure of skeptical arguments. And since Williamson is himself antiskeptical, emphasizing the continuity between ordinary modal cognition and philosophical cognition, he concludes we should give up thinking of our philosophical evidence in the thinly psychological terms of intuitions.

But we do not think that Williamson's arguments can provide much solace for traditional analytic philosophers. For the results of experimental philosophers are not themselves framed in terms of intuitions, but in terms of the counterfactual judgments of various subjects under various circumstances. Although the results are often glossed in terms of intuitions to follow standard philosophical usage, inspection of the experimental materials reveals little talk of intuitions and mostly the direct evaluation of claims. Alexander and Weinberg (2007, p. 72)

(This is one of two responses they give to Williamson; the other is suggestive of the line I will press in §3.)

\footnotetext{
${ }^{13}$ E.g. (Williamson, 2007, 2004).
} 
Alexander \& Weinberg are giving a version of what Cappelen (2014) calls the 'X-PhiDoesn't-Need-Intuitions Reply'. ${ }^{14}$ Although in their presentations of their critiques of armchair methods, experimental philosophers often fall into the language of 'intuition' talk, they are not ultimately relying on any substantive claims about intuitions in important evidential roles; after all, the experimental data themselves do not typically involve the word 'intuition'. For example, although Weinberg et. al's seminal (2001) makes frequent use of 'intuition' language (including in its title, 'Normativity and Epistemic Intuitions'), the application to intuition and to philosophical methodology comes in the interpretation of their data. Their data concern the correlation between demographic variables and answers to questions like this one:

One day Charles is suddenly knocked out by a falling rock, and his brain becomes re-wired so that he is always absolutely right whenever he estimates the temperature where he is. Charles is completely unaware that his brain has been altered in this way. A few weeks later, this brain re-wiring leads him to believe that it is 71 degrees in his room. Apart from his estimation, he has no other reason to think that it is 71 degrees. In fact, it is at that time 71 degrees in his room. Does Charles really know that it was 71 degrees in the room, or does he only believe it? Weinberg et al. (2001, p. 439)

Weinberg et. al observed that students' answers to this question were correlated with demographic variables. This by itself does not straightforwardly imply anything about intuition, unless one assumes that answers to questions invariably express intuitions. ${ }^{15}$ So in this much, I think it's clear that Alexander \& Weinberg are correct: the data that experimental philosophers emphasize does not by itself presume any kind of evidential role for intuition. I do not think, however, that this observation is enough to represent a very substantial defence of the experimentalist critique. For, just as it requires substantive philosophical interpretation to move from the experimentalists' data to claims about intuition, so too does it require substantive philosophical interpretation to move from the data to any kind of challenge to traditional methodology. It is not an explicit tenet of armchair philosophical methods that demographic variables are probabilistically independent from judgments about thought experiments; the experimental results do not directly show a problem. Of course the experimentalist critics are well aware of this fact, which is why they produce extensive arguments concerning the interpretation of these results. Unfortunately for these critics in the present context, many of these arguments $d o$ rely heavily and explicitly on intuition language. In arguing from (a) demographic correlations with thought-experiment judgments to (b) problems for traditional philosophical methodology, critics often commit to contentious claims about how philosophers use intuitions. For example, as highlighted in $\S 1$, Weinberg et al. (2001) explicitly target the view they call 'Intuition-Driven Romanticism', which is defined as a view that takes intuitions as substantive input into a process that yields normative conclusions. Their conclusion - that such views face a serious challengedoes not bear on any method that does not take intuitions as substantive input; if I am

\footnotetext{
${ }^{14}$ Alexander himself may have changed his mind about this; in Alexander (2010, p. 382) he writes that of the idea that "intuitions neither need nor ought to be treated as evidence in philosophy" that "[i]f true, this claim would seem to threaten the significance of experimental philosophy." He goes on to that this claim is not true, but his argument seems to me to conflate persuasive ability with evidence.

${ }^{15}$ Indeed, Chudnoff (2013, pp. 109-112) uses this observation to defend an evidential role for intuitions from experimentalist arguments; Chudnoff (2013) and Alexander and Weinberg (2007) are each defending, from opposite sides of the divide, a kind of independence between questions about intuitions and questions about the experimentalist critique of traditional methodology.
} 
right that traditional armchair philosophical methods on the whole do not use intuitions in this way, then the conclusion of their paper does not bear on traditional armchair methods. So even if Alexander and Weinberg are right that experimental philosophy results do not essentially make use of intuitions, this doesn't show that their analysis doesn't.

Experimental philosophy - even the subset that is its negative 'restrictionist' programis a diverse movement, and we shouldn't assume that every argument against traditional methods makes the same assumption. We must consider the arguments one by one. But it does seem that many experimentalist arguments, at least, do commit to questionable assumptions about intuitions. The argument of the Weinberg et. al paper just mentioned, for example, carries ineliminable commitments to the psychologistic approach to philosophical evidence that Williamson challenges in the passage above, and that I challenged in $\S 1$. In Ichikawa (2014a) I argue that quite a lot of the experimentalist critique carries such problematic commitments. It is worth noting that, contra Ludwig (2007), whether one uses the word 'intuition' is immaterial; the argument that the epistemology does not depend on intuitions in an evidential role does not turn on verbal questions about how to use the word 'intuition'. It just doesn't matter whether 'intuition' is used broadly to refer to all or most judgments or inclinations to judge, or more narrowly to refer only to judgments with a special etiology, or accompanying a particular phenomenology. Williamson argues that no sort of psychological claim is the central evidence; my argument in $\S 1$ has the stronger conclusion that no psychological state is or provides the central evidence. So while I agree with Alexander and Weinberg that one can express the relevant experimental results without the language of 'intuitions', I do not see a clear case that could be made that it's a straightforward matter to modify experimentalist arguments to avoid appeal to problematic assumptions about intuition. This is a point that Cappelen (2014) emphasises - he considers various simple strategies, such as replacing the word 'intuition' with 'philosophical judgment' or 'philosophically relevant judgments about cases' in presentations of these arguments, and argues that the result is not a compelling argument. I think that, at least with respect to many cases, Cappelen is right about this. For example, the view that traditional armchair epistemology proceeds via judgments about cases as central evidential inputs is no more plausible than the view that it proceeds via intuitions; the argument of $\S 1$ counts equally against this view. (Someone who does not judge that wishful thinking isn't a route to justified belief thereby manifests a rational failure, even absent what is suggested to be the central evidence.) I conclude that if, as many of us have recently argued, intuitions do not play evidential roles in traditional philosophical methodology, this fact is relevant for experimentalist critiques; it cannot straightforwardly be ignored or translated away. ${ }^{16}$

I say that the denial of evidential roles has relevance. I do not say, with Herman Cappelen, that it is definitive against experimental philosophy. In §4 I explain why.

\section{Relevance of Experimental Philosophy}

Herman Cappelen thinks, as I do, that the role of intuitions in philosophical methodology has been greatly exaggerated. He also thinks, as I do not, that this renders experimental philosophy irrelevant:

The Big Objection to experimental philosophy is easy to state and should be obvious: philosophers don't rely on intuitions about thought experiments, so

\footnotetext{
${ }^{16}$ Ichikawa (2014a) also contains arguments to this effect.
} 
studies of intuitions people have about thought experiments have no direct relevance for philosophical arguments or theorizing. ... Negative experimental philosophy attacks a practice that doesn't exist. Positive experimental philosophers attempt to support a practice that doesn't exist. In short: If philosophers don't rely on intuitions, then the project of checking people's intuitions is philosophically pointless. Cappelen (2012, pp. 221-2)

Although I do think, as I suggested in $\S 2$, that some experimental philosophy is subject to this criticism, I think that Cappelen goes too far. Not all experimental philosophy is irredeemably based in a misconception about the role of intuitions in traditional philosophical methods. Not even all of the restrictionist critique relies on such misconceptions. It is consistent with the claim that intuitions do not play evidential roles in philosophical methodology that the empirical investigation of intuitions may be relevant for philosophical methodology - even that in theory, they may show deep problems with it. In the abstract, this should be relatively easy to see; there's no contradiction in the idea that a method doesn't make central evidential use of X, but that the study of X may nevertheless be methodologically important for that practice; evidential roles aren't the only roles of epistemic significance. For example, I don't think that judgments about gender play evidential roles in hiring decisions regarding university biology laboratory manager positions; biology professors base such hiring decisions on scientific qualifications. The gender of the candidate isn't evidence regarding one's suitability for such a job; moreover, scientists recognize that gender isn't evidence regarding one's suitability for such a job. (A careful study of the discussions biologists have in their hiring decisions similar to the case studies in Cappelen (2012), I'd conjecture, would not yield evidence of reliance on gender.) None of this is any reason to ignore Corinne Moss-Racusin's (2012), which finds evidence that scientists display systematic subconscious bias against women. Even setting aside the moral and social justice issues here, Moss-Racusin's findings, if true, demonstrate a significant epistemic source of bias - empirical methods have demonstrated a respect in which scientists' beliefs about who would make good laboratory managers go systematically awry. It would be a mistake for a scientist to ignore this critique on the grounds that gender does not play evidential roles in scientific hiring - not because it does, but because evidential roles aren't the only things that matter. One has epistemic reason to consider sources of epistemic defeat, even independently of considerations about what is and isn't evidence.

Some experimentalist critiques of traditional philosophical methods seem naturally interpretable along just these kids of lines. When Stacey Swain et. al (2008) demonstrate that epistemic intuitions are subject to an order effect, this is of epistemic significance to philosophers who are making epistemic judgments - not because the intuitions, or the judgments themselves, or indeed anything psychological, are the evidence they're relying upon-but because these empirical findings constitute a possible reason to doubt one's own ability to respond rationally to the available evidence. Recall the case of Bullwinkle and the chess board. After his blindfold slips, he has all the evidence necessary to know that Natasha can win this turn, but he doesn't know it. Suppose he believes it anyway; although he can't see what the winning move would be, he just has a feeling that this looks like a board where white is in a position to win. The fact that Bullwinkle isn't very good at chess is the sort of thing that ought to give him reason to doubt his judgment - this, even though he does not rely on any claim about his chess skill as evidence. In the same way, order effects in intuitions about philosophical thought experiments are epistemically significant, regardless of whether one is using intuitions in evidential roles. If I learn through empirical means that I tend to be influenced in my judgments by irrelevant factors, this gives me good reason to 
take extra care that I'm not going wrong. ${ }^{17}$ Similarly, when Horowitz (1998) argues that certain controversial deontological moral intuitions are the result of a systematic tendency to overestimate the value of what one thinks of oneself as already having, this kind of psychological data can be relevant for deciding which arguments to accept. Such, of course, is continuous with the traditional armchair project of explaining away intuitions. ${ }^{18}$

Cappelen recognises a version of the experimentalist critique along these lines. In Cappelen (2014), he presents this fictionalised bit of dialogue between himself and a defender of experimental philosophy:

$\mathrm{X}-\mathrm{P}$ : So is your view that we should not care about or try to find biases in philosophical practice? We should just ignore them? Isn't that an irresponsible intellectual attitude?

HC: That's not my view. There are lots of biases in philosophy. Where you an I differ is on how to discover and evaluate those. I think we discover those by doing philosophy - by finding assumptions and presuppositions that bias philosophical reflection. Construed in that way, I see myself as spending a great deal of my time as a philosopher discovering philosophical biases. The discussion at the core of this paper is a good illustration: I think much metaphilosophy is biased in favour of the view that philosophical practice is intuition-based. That bias has distorted metaphilosophical reflections. But discovering that bias, and justifying opposition to it, doesn't involve surveys. It is about doing philosophy like we were trained to do it: it involves thinking hard about arguments, uncovering hidden assumptions and then questioning them. (p. 284)

But one needn't - and, in my view, shouldn't - think of the most plausible versions of the experimentalist critique as in tension with Cappelen's self-attribution here. Cappelen here admits that philosophical biases are epistemically relevant, and that it is worthwhile for philosophers to expend energy in the attempt to detect them; the contrast he draws is between the idea that one should investigate them with surveys, or by 'doing philosophy like we were trained to do it'. If what I have said in this section is right, then this is a false dichotomy (and not just because some philosophers were trained to do philosophy with surveys!). We should think of the experimentalists' surveys, in at least some instances, as a part of 'philosophy like we were trained to do it'. It is, I think, incumbent upon a defender of a restrictionist challenge to explain why her data casts doubt on traditional methods - and I agree with Cappelen that too often, the proffered explanations make unrealistic assumptions about the role of intuitions in those traditional methods - but this isn't always so. As I suggested in Ichikawa (2014a), I think that experimental philosophy tends to be perceived, by many of its practitioners and most of its critics, as a radical departure from standard methods; once we dispense with the assumption of anything like 'intuition-driven romanticism' as a descriptive thesis of traditional methods, we should should consider that perception an error. And the arguments of Cappelen and of Williamson are, I think, very

\footnotetext{
${ }^{17}$ It is of course controversial whether experiments like those of Swain et al. (2008) do give professional philosophers reason to doubt themselves - for example, one might think that philosophers are sufficiently different from the folk who are the targets of these studies. I suspect that in many cases, responses like this on behalf of traditional methods may be defensible. (In Ichikawa (2011) I argue that traditional methods are generally able to meet the experimentalist critiques.) But this is to engage directly with the experimentalist critics; my claim here is that in such cases, this is what is necessary. We cannot sidestep them by denying an evidential role for intuitions.

${ }^{18}$ See Ichikawa (2009) for further discussion of this point.
} 
helpful in showing why that is an error. But most sensitive experimental philosophers today who are expressing concerns about traditional methodology are more careful to express their concerns in ways that do not call for such a radical departure from traditional methods; it is instead a call for a more systematic and scientific treatment of the psychological questions concerning philosophers' biases. Perhaps traditional methods have the resources to satisfy that call $;{ }^{19}$ but it is not one it is legitimate wholly to ignore. ${ }^{20}$

\section{Bibliography}

Alexander, Joshua. 2010. "Is experimental philosophy philosophically significant?" Philosophical Psychology 23:377-389. 8

Alexander, Joshua and Weinberg, Jonathan M. 2007. "Analytic Epistemology and Experimental Philosophy." Philosophy Compass 2:56-80. 7, 8

Brown, Jessica. 2011. "Thought Experiments, Intuitions and Philosophical Evidence." $D i$ alectica 65:493-516. 2

Cappelen, Herman. 2012. Philosophy Without Intuitions. Oxford University Press. 1, 6, 10

-. 2014. "Experimental Philosophy Without Intuitions." In Anthony Robert Booth and Darrell P. Rowbottom (eds.), Intuitions, 269-286. Oxford University Press. 8, 9, 11

Chudnoff, Elijah. 2013. Intuition. Oup Oxford. 2, 4, 5, 6, 8

Deutsch, Max. 2010. "Intuitions, Counter-Examples, and Experimental Philosophy." Review of Philosophy and Psychology 1:447-460. 1

Horowitz, Tamara. 1998. "Philosophical Intuitions and Psychological Theory." Ethics 108:367-385. 11

Ichikawa, Jonathan. 2009. "Explaining Away Intuitions." Studia Philosophica Estonica 2:94-116. 11

—. 2011. "Experimentalist Pressure Against Traditional Methodology." Philosophical Psychology 25:743-765. 11, 12

—. 2014a. "Who Needs Intuitions? Two Experimentalist Critiques." In Anthony Robert Booth and Darrell P. Rowbottom (eds.), Intuitions, 232-256. Oxford University Press. 1, $6,9,11$

Ichikawa, Jonathan Jenkins. 2014b. "Intuitions in Contemporary Philosophy." In Lisa M. Osbeck and Barbara S. Held (eds.), Rational Intuition: Philosophical Roots, Scientific Investigations. Cambridge University Press. 3

Ichikawa, Jonathan Jenkins and Jarvis, Benjamin W. 2013. The Rules of Thought. Oxford: Oxford University Press. 3, 4, 6

\footnotetext{
${ }^{19}$ Ichikawa (2011) argues that it is.

${ }^{20}$ Thanks to Michael Johnson and Jennifer Nado for helpful comments on a draft of this paper; thanks to Jessica Brown, Herman Cappelen, Yuri Cath, Carrie Jenkins, Jonathan Weinberg, and Timothy Williamson for important conversations over the years that helped develop my thinking on these matters. I owe a particular intellectual gratitude to Benjamin Jarvis, with whom I first developed many of the ideas discussed here.
} 
Littlejohn, Clayton. 2013. "No Evidence is False." Acta Analytica 28:145-159. 2

Ludwig, Kirk. 2007. "The epistemology of thought experiments: First person versus third person approaches." In Peter A. French and Howard K. Wettstein (eds.), Midwest Studies in Philosophy, volume 31, 128-159. Blackwell Pub. Inc. 2, 9

Moss-Racusin, Corinne A., Dovidio, John F., Brescoll, Victoria L., Graham, Mark J., and Handelsman, Jo. 2012. "Science faculty's subtle gender biases favor male students." Proceedings of the National Academy of Sciences 109:16474-16479. doi:10.1073/pnas. 1211286109. 10

Rini, Regina A. 2013. "Making Psychology Normatively Significant." The Journal of Ethics 17:257-274. ISSN 1382-4554. doi:10.1007/s10892-013-9145-y. 6

Rizzieri, Aaron. 2009. "Evidence does not equal knowledge." Philosophical studies 153:235242. 2

Swain, Stacey, Alexander, Joshua, and Weinberg, Jonathan. 2008. "The Instability of Philosophical Intuitions: Running Hot and Cold on Truetemp." Philosophy and Phenomenological Research 76:138-155. 10, 11

Unger, Peter K. 1975. Ignorance: A Case for Scepticism. 105. Oxford University Press. 2

Weinberg, Jonathan M. 2007. "How to challenge intuitions empirically without risking skepticism." Midwest Studies In Philosophy 1:318-343. 1

Weinberg, Jonathan M., Nichols, Shaun, and Stich, Stephen. 2001. "Normativity and Epistemic Intuitions." Philosophical Topics 29:429-460. 1, 8

Williamson, T. 2007. The philosophy of philosophy. Blackwell. 1, 7

Williamson, Timothy. 2000. Knowledge and its limits. Oxford: Oxford University Press. ISBN 0198250436 (alk. paper). 2, 3

—. 2004. "Philosphical 'Intuitions' and Scepticism about Judgement." Dialectica . 7 